\title{
PREPARATION OF CLINICAL PRECEPTORS
}

Dr Yvonne Botma: University of the Free State, Associate Professor June Jeggels: University of the Western Cape, Professor Leana Ria. Uys: University of KwaZulu-Natal.

\begin{abstract}
Nursing students in South Africa are mostly dissatisfied with clinical teaching and accompaniment in clinical practice. Consequently final year students feel ill prepared for their roles as registered nurses. Many factors, for example the shift from hospital based training to higher education, staff shortages, high acuity levels, greater treatment sophistication etc contribute to the dilemma of inadequate support of students during clinical placements. Preceptors that are either appointed by the nursing education institution or health service may address the issue of inadequate support of students. However, preceptors should be well trained to facilitate learning in the complex and dynamic clinical environment. This article gives an outline for the preparation of preceptors and includes selection criteria for candidates, the content of a training programme, as well as the assessment of programme outcomes.
\end{abstract}

Keywords: Clinical preceptors; training; guided practice

\section{Introduction}

The clinical learning experiences of nursing students in South Africa have been explored in a number of studies. One study, done in Limpopo (Mabuda, Potgieter and Alberts, 2008) looked at how students experienced their clinical placements. The results were mainly negative, with students complaining of limited support and teaching while they were in clinical settings. Such settings were over-crowded which impacted negatively on students' ability to learn, as well as resulting in the inappropriate allocation of work so that students spent most of their time doing menial tasks, without being allocated challenging work in line with their learning needs. Negative relations between students and ward staff was another problem. Students indicated that being placed in a clinical setting for 14 days was too short a period, and also that their theory was sometimes taught only after they had done the practical work.

Another study looked specifically at clinical facilitation (Cassimjee \& Bhengu, 2006) and found that students receive very little clinical teaching. A total of $79 \%$ of the students in this KZN study were dissatisfied with their clinical facilitation, and $23 \%$ indicated that they had not been visited in a clinical setting by a preceptor during the last 3 months. A further $32 \%$ were seen only once in the three months, and a further $15 \%$ twice. In a Gauteng study, Waterson et al (2006) found that theory and practice were not integrated and that students lacked role models. Dhavana-Malelesele, Tjallinks and Norval, (2001) also discovered that students did not use the relevant theory in administering a unit, in relation to ethical and legal issues, and pharmacology when this information applied in clinical situations. Van Rhyn and Gontsana (2004) looked at clinical placements in psychiatric settings in the Free State and found average to high levels of stress in students due to ineffective teaching, poor management, registered 
nurses (RNs) being detached from their teaching roles, poor staff relations, over-reliance on the medical model and patient neglect.

It is then no surprise that Carlson, Kotze and van Rooyen (2005) found in the Eastern Cape that final-year students generally did not feel prepared to fulfil their roles as RNs. They also complained about a lack of role models, indicating furthermore that they were not given enough opportunities to practise management skills and were not acknowledged by the multi-professional team members. This left them with a range of negative feelings, such as powerlessness, fear and frustration.

\section{The context of preceptor training}

In South Africa, the British model of nurse training based on the apprenticeship model was introduced at the inception of professional education. This model places students in clinical services to work as part of a nursing team to provide nursing care, while being supervised and taught by registered nurses in the services. Over the last twenty years, however, nursing education has changed internationally, and also in this country. Nursing education, together with that of other health professionals, moved out of hospital schools into higher education institutions, bringing profound changes.

Internationally, studies investigating this shift to higher education have identified a number of problems. Clinical training devolved to practising nurses, who have found it difficult to accommodate a teaching role within their existing roles. The practising nurses are often burdened by high clinical workloads and have not been prepared to facilitate student learning. However, this model of clinical learning facilitated by practising nurses allows for authentic socialization into the world of the nurse (Mannix et al, 2009; Hackmann, 2007; Myall et al, 2008). The health system is challenged by an acute shortage of experienced nurses, leading to higher expectations of new graduates, as well as limited exposure to role models in the clinical areas (Mannix et al, 2009). These areas have, over the last thirty years, become more complex due to higher acuity levels, greater treatment sophistication and shorter care periods. These changes in the clinical areas often lead to over-crowded and under-resourced clinical areas, with a shortage of goodwill and commitment to teaching students (Mannix, et al, 2009). It is also difficult to find clinical preceptors in adequate numbers when large cohorts of students have to be accommodated. Preceptors often have limited preparation for teaching, and scant knowledge of the curriculum. Students sometimes experience repeated changes in clinical preceptors and these preceptors might not be familiar with all the clinical areas (Happel, 2009; Hossein et al, 2010).

In South Africa, the system of having "clinical instructors" employed by training hospitals to support and train students and act as liaison personnel between the Nursing Education Institutions (NEIs) and the services, was gradually discontinued during the 1980 to 1990 timeframe. In some cases they have been replaced by clinical preceptors employed by NEls in a full-time or part-time capacity. More recently, there has been a move to re-introduce the clinical instructor cadre, and in some provinces an effort has also been made to train registered nurses employed in health services to take on the task of supporting and training students as part of their professional role. Nurses interested in preceptor training might therefore be employed in this capacity either by health services or NEls, or may take on this role in addition to their clinical role. A preceptor is an experienced and competent professional nurse who is 
positive about nursing, students and herself. She serves as a clinical teacher in the clinical setting and is employed by a Higher Education Institution (HEI).

\section{The role of the preceptor}

The main role of the preceptor is to facilitate learning in the clinical unit. Learning is a personal, social and emotional activity. Therefore, the preceptor has to create an environment conducive to learning by introducing the student to the clinical working environment, and supporting them to make optimum use of this environment for their own learning. Four main roles can be distinguished from each other:

Orientation includes introducing the student to the rest of the health-care team, orientating the student to the daily routine of the unit, as well as explaining hand-over procedures and reporting systems (Smedley \& Penny, 2009) and pointing out resources such as the Policy File or reference books available in the unit. By performing these small services, anxiety is reduced and students will be better able to learn.

Guided practice involves the preceptors and students agreeing on the learning outcomes for the duration of the placement period, the preceptor demonstrating care to the student or vice versa. Preceptors should assist the students in achieving their set of learning outcomes whether these apply to knowledge generation, the development of psychomotor skills or integration of theory and practice (Omansky, 2010; Wade m \&Hayes, 2010).

Authentic formative assessment is another role of clinical preceptors. This role implies that they assess the performance of students in actual role-taking situations so that holistic functioning can be assessed. Students receive feedback as to how they perform in the actual situation, where many factors are unpredictable, time is limited, resources might be scarce and real patients are involved.

Through role modelling, preceptors demonstrate complex professional role fulfilment by showing competent time management, planning and prioritization of patient care. Professional behaviour is demonstrated through adhering to the profession's legal and ethical guidelines (Smedley and Penny, 2009). Students are thus socialized into their professional role and identity (professional socialization).

\section{Techniques used by preceptors}

Preceptors have to assist students in developing clinical judgement (critical thinking and problem solving skills) (Huybrecht et al., 2011). Professional nurses should be able to render appropriate evidence-based nursing care founded on their clinical judgments (Tanner, 2006). Becoming competent in rendering high quality evidence-based nursing care requires integration of theory and practice. This is a process that should be facilitated by the preceptor through techniques such as demonstration, questioning, reflection, feedback and other techniques.

Most of the techniques used by preceptors foster reflection in-action and/or on-action, but vary in the degree to which they stimulate deep reflection. Tecniques commonly used by preceptors are thinking aloud, demonstration, one-minute technique, case presentation, feedback, cueing, questioning and guided reflection.

The "thinking-aloud" technique augments role-modelling because preceptors voice the options, decisions and debates about care situations. This technique assists students to connect the practice to decision-making. When the student uses "thinking-aloud", the preceptor can follow the student's clinical 
reasoning process. However, it is not always appropriate to verbalise everything in front of a patient (Ness et al., 2010; Forneris and Peden-McAlpine, 2007; Burns et al., 2006).

Demonstration occurs when the preceptor demonstrates clinical competencies while the students observe the application of classroom learning in practice (Lundberg, 2008).

The one-minute preceptor technique activates learning through three easy steps. According to Burns et al (2006) the student must first explain what he/she thinks about the particular case. Then every observation must be substantiated by evidence from previous clinical experience, coursework or readings. Finally, the preceptor immediately gives feedback on what was correct or incorrect or not noticed. This technique allows students to realise some general rules that apply to the situation and the specific context. It is quick and easy to use.

Case presentations afford students the opportunity to demonstrate their ability to report pertinent findings, generate differential diagnoses and develop appropriate management and follow-up care plans. Self-evaluation allows them to critically analyse their learning in a specific setting. Questions that support this process are, for example: "how well do you think you did?" or "how could you have done this differently?" (Wade and Hayes, 2010; Clynes and Raftery, 2008; Burns et al., 2006). Case presentations take a lot of time, but if the hand-over is used to mimic case presenting, this could augment learning.

Giving verbal and non-verbal feedback to a student is a valuable technique when used correctly. Feedback should be constructive and must start and end with a positive comment. Furthermore, the focus should be on the behaviour and work performance and not on the character of the person. It must be highly specific to what occurred and should be provided in terms of specific targets and standards (Wade and Hayes, 2010; Clynes and Raftery, 2008). Yonge, Myrick and Furguson (2011) are of the opinion that feedback should be gentle and should focus more on helping than correcting. If constructive feedback is given the student will gain specific insight into their performance and options for improving practice can be explored (Clynes and Raftery, 2008).

Providing a verbal or non-verbal cue to a student who performs a task creates a positive learning environment. By nodding or showing a thumbs-up sign students are encouraged that they are on the right track. It keeps them safe and efficient while mastering the steps of a skill that may not yet be automatic (Burns et al., 2006).

Questioning is a technique that most preceptors use. However, students may perceive it as threatening and become anxious. It is thus a skill that implies that the preceptor is able to listen, read facial expressions and is able to adjust questions to the learners' level of understanding (Beckman and Lee, 2009). Through questioning, the preceptor aims to determine what the student knows, to encourage reflection, to challenge the student and promote further insight and to foster critical thinking skills (Ness et al., 2010; Myrick and Yonge, 2002). Box 1 contains a few examples of questions a preceptor may find useful. Key points to consider when formulating questions are the following:

- Use an appropriate tone of voice at the right time and place.

- Avoid bombarding student with questions. Questions should be challenging but not threatening.

- Consider the academic level of the student and the learning outcomes.

- Formulate clear, unambiguous questions on a high cognitive level. 
- Listen carefully to the answer, observe the body language of the student and respond constructively.

- $\quad$ Allow sufficient time for the student to answer the question.

- Move from simple to more complex questions (Ness et al., 2010; Beckman and Lee, 2009; Forneris and Peden-McAlpine, 2006; Myrick and Yonge, 2002).

Examples of questions to ask

- Why ...

- What do you think is happening?

- How do you link it to the patient data?

- What is the information saying to you?

- What information do you need to assist you in making a decision?

- Are there any patterns that you should pay attention to?

- Which cues are leading you to draw a conclusion?

- What do you want to achieve?

- How can you change the situation?

- What do you expect to happen when you do this?

- How will your actions achieve the desired outcomes?

- What aspects of this situation were significant?

- How do you link this experience with what you already know?

Figure 6.1: Generic questions that preceptors use

Reflecting in-action and on-action is an active thinking process during which students try to make sense of the experience. Boud (1985), cited in Ness et al. (2010: 44), describes reflective practice as "turning experience into learning". Through reflection on their practice, students grow professionally and emotionally. Furthermore, such reflection develops their clinical decision-making skills (Treadway and Chatterjee, 2011; Ness et al., 2010). Forneris and Peden-McAlpine (2007) state that reflection must be used to structure student's thinking and reasoning on the learning experience. Most people find it difficult to reflect and to learn from the process. It is thus the preceptor's responsibility to facilitate reflection by giving students some guidelines. Reflection consists of three phases - namely, the description of the context and clinical situation, critical reflection and integrating learning into future practice.

- Description of the context and clinical situation may be facilitated by asking the student to describe a stimulating or distressing situation by answering questions as to who was involved, where the incident occurred, what happened, when did it happen, and how they felt. Students should be cautioned about confidentiality and should not mention names (Nielsen, Stragnell and Jester, 2007; Forneris and Peden-McAlpine, 2007).

- According to Forneris and Peden-McAlpine (2007), critical reflection should provide answers to the following questions, amongst others:

- What did you notice about the situation?

- What did you think were the causes and possible resolutions?

- What additional information would have been helpful? 
- What was your final decision?

- What evidence supported your decision?

- What was your goal for the patient?

- What interventions did you implement to achieve the goal?

- What personal and professional values and beliefs influenced you?

- The last phase of reflection is to integrate learning into future experiences. Therefore, the student needs to create a strong image that will immediately activate existing knowledge when a similar situation is encountered. Students thus need to analyse the context and situation to identify what stood out for them. By asking them what they would have done differently or what additional knowledge, information or skills they needed to manage a similar situation in future could guide them to improve their practice. Reflection ends when asking them to describe two or three ways their nursing skills expanded during the experiential learning situation (Forneris and PedenMcAlpine, 2007; Nielsen, Stragnell and Jester, 2007).

Being a preceptor is challenging and the preceptor needs to have an in-depth understanding of the nature and dynamics of a complex process (Abbott, Goosen and Coetzee, 2010). It is thus not every nurse who has the makings of an effective clinical preceptor.

\section{Preceptor preparation in South Africa}

Two education and training programmes have recently been developed in South Africa - the oldest at the University of the Western Cape (UWC) and the other at the University of the Free State (UFS).

The programme at the UWC is a two-week full-time short learning course during UWC's summer / winter school programmes. Teaching and learning strategies in this programme include interactive lectures, case studies, small group activities, preceptor-student encounters in simulated (videorecorded) and real service settings and reflective discussions. The programme outcomes include, amongst others:

- Application of the principles of clinical teaching and learning within the context of adult education;

- How to demonstrate an understanding of the preceptor role;

- Effective management of a preceptor-student encounter;

- How to initiate and evaluate a tailor-made skills training programme.

Assessment of competence is done based on a portfolio of evidence (including a reflective journal of experiential learning) submitted by preceptor candidates. UWC has trained 50 preceptors through this programme and is currently in the process of evaluating the results.

The UFS programme takes three full days, one month apart, and contains a copious amount of homework. Training includes teaching preceptors how to:

- $\quad$ Stimulate clinical judgment;

- Use questioning in the process of facilitating such judgment;

- Facilitate reflection;

- Talk aloud while role-modeling;

- Assess students in the clinical situation; 
- $\quad$ Give constructive feedback.

So far, UFS has only trained their own staff through this programme, but they are in the process of rolling it out further.

\section{Guidelines for the preparation of preceptors}

The following guidelines were developed, based on the literature and the experience of the two universities offering training in South Africa. These were then discussed at a FUNDISA business meeting before being approved for implementation.

\section{Programme development}

Preceptor training may be presented as a continuing education programme, a stand-alone on-line module/s or as part of a postgraduate study programme. The programme is generally designed and presented by a higher education institution (university or college) in collaboration with a service facility. The usual steps in the development of such a programme should be followed:

1.1 Do a situation analysis to identify the need for such a programme in the region, the resources (human and clinical) that might be used in offering the programme, as well as targeting the stakeholders and their interests.

1.2 Irrespective of the mode of delivery, the programme needs to be developed and approved by the relevant structures within the institution offering the programme and a budget secured. Accurate costing needs to occur and a decision made regarding the weighting of the programme in terms of the number of continuing professional development points / credits to be allocated once the candidate has successfully completed the programme.

1.3 A programme guide needs to be developed that specifies the mode of delivery, programme outcomes and assessment modalities, amongst others.

1.4 The necessary learning resources should be put in place; for instance, books ordered, electronic learning support set-up, and mentors appointed if potential preceptors are going to be mentored into the new role.

\section{Selection of candidates for preceptor training}

The selection of preceptors is aimed at determining which individuals would best match the preceptorship role.

To match the person to the role might require a structured selection process to include specific selection criteria and a screening interview (Jooste, 2010). However, this limits the training to "ideal" candidates and may inhibit growth in other potential candidates.

Ideally, the selection of prospective candidates should be done by the stakeholders involved in the clinical teaching endeavour, such as managers from the clinical settings and academics from the training programme. 
Requirements:

- In all cases the prospective preceptors should be qualified professional nurses with a degree of clinical experience. If the preceptors need to be involved in teaching specialist nurses, they have to have the relevant specialist qualification and the necessary experience that will make them a nurse specialist, or an expert in the area.

- The attitude to teaching must be characterized by a willingness to teach and an interest in students and learning (Yonge et al., 2007; Smedley, 2008). This includes an interest in their own learning, either through formal study or informal reading and study.

- Good communication and decision-making skills are essential, since the preceptor always has to negotiate different systems (relating both to education and health-care) and deal with challenging situations.

\section{Duration of the programme}

Since preceptor training has to provide a theoretical orientation to new roles, as well as develop an appropriate attitude (including self-confidence in these roles) and the essential skills, it needs to be a formal process which includes practise opportunities. Based on the experience in South Africa, 10 credits (100 notional hours) are seen as the minimum for a programme that addresses the role comprehensively. This provides a little more than two weeks of full-time study which is similar to the successful UWC programme.

\section{Content of the programme}

Most of the preceptor training programmes utilize an adult learning model. The content should address both in theory and practice all four roles described above. It should also provide exposure to, and reflection on, all the techniques identified.

The content of the preceptor training programmes offered in various contexts should include, amongst others:

- Knowledge about adult learning principles, learning styles and teaching strategies;

- Application of all four roles and all seven techniques in the context of the clinical teaching and learning environment;

- Facilitating the creation of a clinical learning environment that is student-friendly. If the training programme is designed to prepare clinical preceptors for a specific specialized unit, the content is developed in collaboration with experts from the field of specialization or the specific unit, and could include specific practice components.

Some of the following models or theories may be used to underpin the educational offering:

- The adult learning model (Knowles, 1984) could guide the inclusion of adult learning principles into the preceptor programme; i.e. that adults are self-directed, goal-orientated and practical learners who are able to draw on prior life experiences.

- The experiential learning theory (Kolb, 1984) can be used to plan the clinical teaching/learning activities included in the course outcomes, as it aligns well with clinical skills training. 
- The preceptorship model (Happel, 2009) is a useful resource for planning a clinical preceptor programme that will involve all the stakeholders; i.e. the preceptor, student, university and clinical organization.

\section{Presentation of the programme}

Since the clinical preceptors are being prepared to teach in non-classroom settings, it is important to use mainly these settings to teach them their new role. The presentation mode for a preceptor programme varies, but includes, amongst others:

- Interactive contact sessions (face-to-face or on-line);

- Coaching sessions;

- Small group work;

- Reflection and reflective journaling;

- $\quad$ Portfolio development;

- Sessions in clinical simulation;

- Debriefing exercises.

The more the programme can demonstrate the use of the same techniques to be used by the preceptor in practice, the more successful learning will be.

\section{Assessment of programme outcomes}

The assessment of preceptor candidates should be done in terms of the programme outcomes.

Assessment techniques which provide the preceptors with experience in techniques they may apply to their students in the clinical setting, should be given priority. For instance, Burns and Northcutt (2009) included questions for consideration after case-studies and also a pre-test and post-test evaluation of the success of achieving the programme objectives. Singer (2006) used a variety of approaches, including skills assessment tools, competency assessments and post-class evaluations.

\section{Conclusion}

Clinical teaching has always been seen as a component of the educational responsibilities of nurse educators, however, with the development of a specific position such as that of a clinical preceptor, the need for a shorter, targeted training programme has been identified. In the proposed Clinical Training Model, preceptors play a major role and, across the country, Nursing Education Institutions will have to recruit, train and deploy them to augment the learning of student nurses in practice.

\section{References}

Abbott, P., Goosen, X. and Coetzee, J. 2010. Developing and supporting coordinators of structured mentoring schemes in South Africa. Available: http://www.sajhrm.co.za [Accessed 3 Dec 2010].

Ashford, Lawrence J. 2010. Teach practical skills before nursing courses start. Nursing Standard 24 (48): 24. 
Beckman, T.J. and Lee, M.C. 2009. Proposal for a collaborative approach to clinical teaching. Mayo Clinic Proceedings 84 (4): 339-344, doi: 10.4065/84.4.339.

Burns, C., Beauchesne, M., Ryan-Krause, P. and Sawin, K. 2006. Mastering the preceptor role: Challenges of clinical teaching. Journal of Pediatric Health Care 20 (3): 172-183.

Burns, H.K. and Northcutt, T. (2009) Supporting Preceptors: A three-pronged approach for success. The Journal of Continuing Education in Nursing 40 (11): 509-513.

Carlson, S., Kotze, W.J., and van Rooyen, D. 2005. Experiences of final year nursing students in their preparedness to become registered nurses. Curationis 28 (4): 65-73.

Carlson, E., Wann-Hansson, C. and Pilhammer, E. 2009. Teaching during clinical practice: Strategies and techniques used by preceptors in nursing education. Nurse Education Today 29 (2009): 522-526.

Cassimjee, R., Bhengu, M.P. 2006. Student nurses' perceptions of their contact time with stakeholders in their clinical instruction. Curationis 29 (4): 47-53.

Clynes, M.P. and Raftery, S.E.C. 2008. Feedback: An essential element of student learning in clinical practice. Nurse Education in Practice 8: 405-411.

Davhana-Maselesele, M., Tjallinks, J. E. \& Norval, M. S. 2001. Theory-practice integration in selected clinical situations. Curationis 24 (4): 4-9.

Forneris, S. and Peden-McAlpine, C. 2007. Evaluation of a reflective learning intervention to improve critical thinking in novice nurses. Journal of Advanced Nursing 57 (4): 410-4221.

Happel, B. 2009. A model of preceptorship in nursing: Reflecting the complex functions of the role. Nursing Educator Perspectives 30 (6): 372-376.

Hossein, K.M., Fatetemeh, D., Fatemeh, O.S,, Katri, V.J., and Tahereh, B. 2010. Teaching style in clinical nursing education: A qualitative study of Iranian nursing teachers' experiences. Nurse Education in Practice 10 (1): 8-12.

Huybrecht, S., Loeckz, W., Quaeyhaegens, Y., De Tobel, D. and Mistiaen, W. 2011. Mentoring in nursing education: Perceived characteristics of mentors and the consequences of mentorship. Nurse Education Today $31: 274-278$. 
Kline, K.S., Hodges, J. 2006. A rational approach to solving the problem of competition for undergraduate clinical sites. Nursing Education Perspectives 27 (2): 80-83.

Knowles, M. 1984. Andragogy in Action. San Francisco: Jossey-Bass.

Kolb, D.A 1984. Experiential learning. Englewood Cliffs: Prentice Hall.

Lundberg, K.M. 2008. Promoting self-confidence in clinical nursing students. Nurse Educator doi:10.1097/01.NNE.0000299512.78270.d0, p. Online.

Mabuda, B.T., Potgieter, E., and Alberts, U.U. 2008. Student nurses' experience during clinical practice in the Limpopo Province. Curationis 31 (1): 19-27.

Mannix, J., Wilkes, L. and Luck, L. 2009. Key stakeholders in clinical learning and teaching in Bachelor of Nursing programs: A discussion paper. Contemporary Nurse 32 (1-2): 59-68.

Myrick, F. and Yonge, O. 2002 Preceptor questioning and student critical thinking. Journal of Professional Nursing 18 (3): 176-181.

Ness, V., Duffy, K., McCullum, J. and Price, L. 2010. Supportiing and mentoring nursing students in practice. Nursing Standard 25 (1): 41-46.

Nielsen, A., Stragnell, S. and Jester, P. 2007.Guide for reflection using the clinical judgment model. Journal of Nursing Education 46 (11): 513-516.

Omansky, G. 2010. Staff nurses' experiences as preceptors and mentors: an integrative review. Journal of Nursing Management 18: 697-703.

Singer, C. 2006. A preceptor training program model for the hemodialysis setting. Nephrology Nursing Journal 33 (6): 623-629.

Smedley, A.M. 2008. Becoming and being a preceptor: A phenomenological study. The Journal of Continuing Education in Nursing 39 (4): 185-191.

Smedley, M. and Penny, L. 2009. A partnership approach to the preparation of preceptors' nursing education perspectives. New York: National League for Nursing. 
Tanner, C.A. 2006. Thinking like a nurse: A research-based model of clinical judgment in nursing'. Journal of Nursing Education 45 (6): 204-211.

Treadway, K. and Chatterjee, N. 2011. Into the water - The clinical clerkship'. New England Journal of Medicine 364 (13): 1190-1193.

Van Rhyn, W.J.C. and Gontsana, M.R. 2004. Experiences by student nurses during clinical placement in psychiatric units in a hospital. Curationis 27 (4): 18-27.

Wade, G. and Hayes, E. 2010. Challenges and opportunities associated with preceptored community health clinical experience. Public Health Nursing 27 (5): 459-467.

Waterson, E., Harms, E., Qupe, L., Maritz, J., Manning, M., Makobe, K. and Chabeli, M. 2006. Strategies to improve the performance of learners in a nursing college - Part 1: Issues pertaining to nursing education. Curationis 29 (2): 56-65.

Yonge, O., Billay, D., Myrick, F. and Luhanga, F. 2007. Preceptorship and mentorship: Not merely a matter of semantics. International Journal of Nursing Education Scholarship 4 (1): 1-13.

Yonge, O., Myrick, F. and Furguson, L. 2011. The process of developing a framework to guide rural nurse preceptors in the evaluation of student performance. Nurse Education in Practice 11: 76-80. 